\title{
Growth responses of aquatic hyphomycetes to different sources of carbon and nitrogen
}

\author{
Saraswati Bisht \\ Department of Botany, Govt. Degree College, Champawat (Uttarakhand), INDIA \\ E-mail: saraswatibisht@yahoo.co.in
}

Received: March 3, 2013; Revised received: M ay 1, 2013; Accepted: J uly 23, 2013

\begin{abstract}
Assessment of different sources of carbon and nitrogen in terms of dry weight biomass of four selected aquatic hyphomycetes viz; F lagellospora penicilloides Ingold, Pestalotiopsis submersus Sati and Tiwari, Tetrachaetum elegans Ingold and Tetracladium marchalianum De Wildeman was made for their nutritional requirements. Eight carbon sources and ten nitrogen sources were singly added to the basal media in order to provide $4 \mathrm{~g}$ of carbon and $1 \mathrm{~g}$ of nitrogen per litre of distilled water. Among carbon compounds glucose and sucrose were found to be most suitable sources of carbon for all the four fungal isolates, where as fructose proved good for T. marchalianum, P. submersus and F.penicilloides fairly. Cellulose was found a poor source of carbon for the growth of all these isolates. The inorganic sources of nitrogen were found as good nitrogen sources with preference for ammonium ions. Suitability of amino acids was found variable from species to species for nitrogen. T.elegans and T.marchalianum had their maximum growth in asparagines, whereas, P. submersus had their highest growth in proline. Cysteine was observed as a good source of nitrogen for almost all the fungal isolates used. Anova calculated for these observed data showed significant variations in the dry weight production of different fungal species grown in different sources of carbon and nitrogen $(\mathrm{P}<0.01)$.
\end{abstract}

Keywords: Aquatic hyphomycetes, Carbon sources, Nitrogen sources, Nutritional requirements

\section{INTRODUCTION}

Aquatic hyphomycetes, a novel group of "Fungi Imperfecti" which completes its life on submerged decaying plant materials in well-aerated water, are characterised by their peculiar tetraradiate, triradiate or sigmoid conidia, represents asexual stages of Ascomycotina and Basidiomycotina. Ingold $(1942,1975)$ for the first time recognized these fungi as aquatic hyphomycetes, later these were also known as water borne conidial fungi and Ingoldian fungi. The diversity of aquatic hyphomycetes in the fresh water habitat has a particular significance in the decomposition of submerged plant materials, nutrient release and productivity. These fungi play a key role in unlocking and distribution of energy in any running fresh water bodies.

Due to the immense importance of Aquatic hyphomycetes in decomposition biology, some of the fast decomposing species were developed as biofertilizers and bioagents (Sati and Tiwari, 1997). Endophytic study of Aquatic hyphomycetes reveals that these fungi play key role in plant health and can be used as plant growth promoters (Sridhar and Raviraza 1995). Some of these fungi are reported to have antibacterial activity and can be used against bacterial infection in plants (Gulis and stephanovich, 1999).
These fungi also play a key role as pollution indicator due to their absence in polluted or stagnant water bodies like ponds, pools, ditches and prevalence in any running fresh water body (Manoharachary, 1986).

A great deal of studies on the occurrence and distribution of these fungi has been made in various parts of world (Webster and Descales, 1981, Sridhar et al., 1992, Marvanova, 1997) including Kumaun Himalaya, India (Sati et al., 2002, Sati and Joshi, 2011). Some field studies on physiological factors effecting the growth of aquatic hyphomycetes have been made (Suberkropp 1984, Field, 1985 and Thompson and Barlocher, 1989). Recenty comprehensive ecological studies on diversity/ function relationships in microcosms have been carried out (Barlocher and Corkum, 2003, Dang et al., 2005).

These studies focused not only on the diversity of aquatic fungi, but also on their function as decomposer organisms. But there is still no information available on physico-chemical requirements of aquatic hyphomycetes accepts Ranzoni (1951) and Thornton (1963, 1965). Thus, an investigation on the nutritional requirements of some commonly occurring aquatic hyphomycetes, isolated from the streams of the temperate zone in Kumaun Himalaya, was carried out to determine their carbon and nitrogen requirements. 


\section{MATERIALS AND METHODS}

Four fungal isolates of aquatic hypomycetes ( $F$. penicillioides, P. submersus, T. elegans and $T$. marchalianum) were selected for the present investigation. Monohyphal cultures of these fungi were obtained by single spore isolation. These cultures were maintained at $15 \pm 2^{\circ} \mathrm{C}$ on $2 \%$ Malt Extract Agar slants with initial $\mathrm{pH} 6.5$ and in petri dishes containing malt extract agar (Sati et al., 2002). These strains were previously deposited in the culture collection of the Kumaun University Mycological Specimens (KUMS), Nainital, India.

The basal medium consisted of $4.0 \mathrm{~g}$ glucose, $1.0 \mathrm{~g}$ $\mathrm{KH}_{2} \mathrm{PO}_{4}, 0.2 \mathrm{~g} \mathrm{MgSO}_{4} .7 \mathrm{H}_{2} \mathrm{O}, 0.02 \mathrm{~g} \mathrm{FeCl}_{3} .6 \mathrm{H}_{2} \mathrm{O}, 1.0 \mathrm{~g}$ Difco yeast extract and 1 litre of distilled water (Ranzoni, 1951). To find out the carbon requirement the basal medium was prepared without glucose and then eight carbon containing compounds (glucose, fructose, sucrose, xylose, starch, cellulose, dextrin and lactose) were added separately to the basal media in sufficient quantities to create a concentration equivalent to $4.0 \mathrm{~g}$ of carbon $/ \mathrm{L}$ of medium (Thornton,1963). Three replicates were used in each experiment for each fungal isolate. Uniform circular agar blocks ( 5 m.m. diameter) containing mycelial mat were cut from a 15 days old culture plate and transferred into sterilized conical flasks (100 ml. cap.) containing 25 $\mathrm{ml}$ of basal medium (Sati et al., 2002).

For nitrogen nutrition, the yeast extract was replaced by different nitrogen containing compounds (Inorganicammonium sulphate and potassium nitrate and organic amino acids-alanine, arginine, asparagine, cysteine, proline, phenylalanine, isoleucine and methionine) and Biotin and Pentothenic acids (each $5 \mu \mathrm{g} / \mathrm{L}$ ) were added as growth stimulators. All the nitrogen sources were taken separately in such a quantity that the final concentration of nitrogen was $1.0 \mathrm{~g} / \mathrm{L}$ of medium (Thornton, 1965).

The inoculated flasks were incubated at $20 \pm 2^{\circ} \mathrm{C}$ in the dark and casually shaken for aeration. After 15 days of incubation, the net hyphal growth of the fungus was determined in terms of mycelial dry weight. Adhered agar medium from the mycelial mat was removed by staining through a filter paper (Whatman No.1) then mycelial mat was rinsed with distilled water 3-4 times to remove traces of basal medium and it was placed in a drying oven at $80^{\circ} \mathrm{C}$ for $4 \mathrm{hrs}$., then fungal biomass was weighed with a digital electronic microbalance (Thornton, 1965).

\section{RESULTS}

The growth results of these fungal isolates are given in Table 1, and Figures 1 and 2.

The glucose and sucrose were found to be the most suitable carbon sources for all these fungal isolates, whereas fructose was found to be equally good for $T$. marchalianum and P. submersus. Xylose also supported good growth of three of the fungal isolates but poor growth of T. elegans. Starch was found to be a good source of carbon for T. elegans and P. submersus in comparison with T. marchalianum and F. penicillioides. Cellulose was observed to be a poor source of carbon for all the studied fungi. Dextrin was also found to be a good carbon source for the growth of these fungi. Lactose supported moderate growth of $P$. submersus and $F$. penicillioides but was a poor carbon source to $T$. marchalianum and T.elegans (Fig. 1). It is evident from the Table 1 that all the test strains assimilated both nitrate and ammonium ions but to a varying extent. Biomass data indicates higher preference for ammonium ions. Similarly, all the test strains utilized all the provided amino acids.

Fig. 2 shows the extent to which the different amino acids supported the growth of the four test strains. Relative growth rate $(66 \mathrm{mg})$ of $\mathrm{T}$. elegans was generally observed when the medium was supplemented with the sulphuric amino acids cysteine or methionine. Proline followed by isoleucine and phenylalaine was found to support maximum growth of P.submersus and F. penicillioides (dry weight biomass between $250 \mathrm{mg}$ and $341 \mathrm{mg}$ ), both with an identical preference pattern. But the same three amino acids represented a poor nitrogen source for T.elegans and T. marchalianum. For the latter species best mycelia growth (dry weight biomass between 245 $\mathrm{mg}$ and $316 \mathrm{mg}$ ) was observed with alanine, asparagine and arginine.

\section{DISCUSSION}

Aquatic hyphomycetes occur abundantly on abscised, mature and submerged leaf litter in running fresh water (Sati and Tiwari 1997, Sati et al., 2002, Sati and Joshi, 2011). These fungi have nutritional advantages over some of their close competitors (viz. the Zoosporic fungi, bacteria and zoo planktons) because decaying leaves

Table 1. Average dry weight $(\mathrm{mg} \pm \mathrm{SE})$ yields of four fungal isolates in nitrate and ammonium ions as nitrogen sources.

\begin{tabular}{lcccc}
\hline \multirow{2}{*}{$\begin{array}{l}\text { Inorganic nitrogen } \\
\text { sources }\end{array}$} & \multicolumn{4}{c}{ A verage dry weight yield $(\mathrm{mg} \pm \mathrm{SE})$} \\
\cline { 2 - 5 } & T. elegans & T. marchalianum & P. submersus & F. penicillioides \\
\hline Ammonium sulphate & $27.0 \pm 0.4$ & $88.3 \pm 0.2$ & $254.3 \pm 0.5$ & $216.3 \pm 0.6$ \\
Potassium nitrate & $18.7 \pm 0.2$ & $75.0 \pm 0.4$ & $205.5 \pm 0.7$ & $203.0 \pm 0.3$ \\
\hline
\end{tabular}



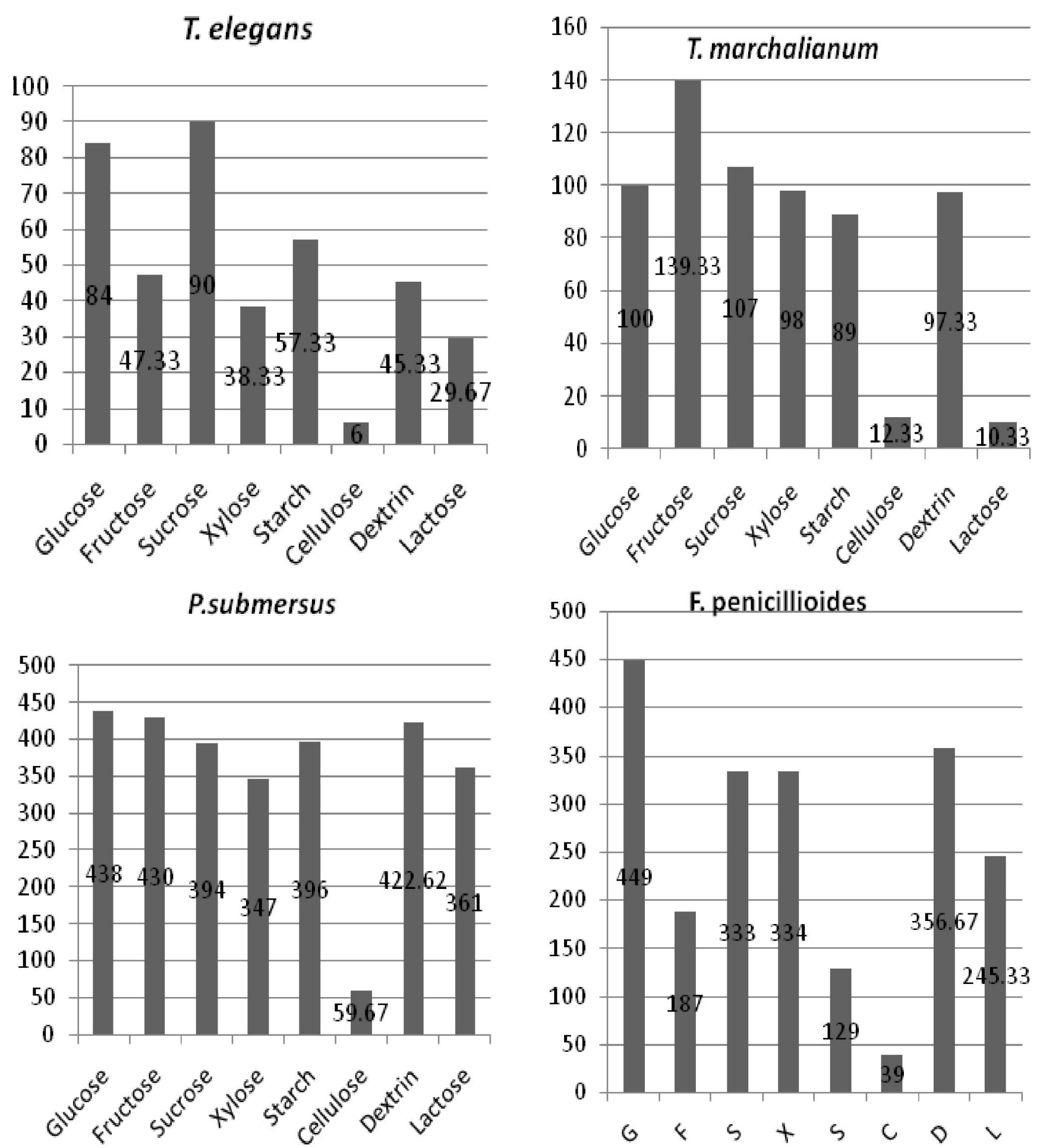

$\mathrm{Fig} \mathrm{1.} \mathrm{Average} \mathrm{dry} \mathrm{weight} \mathrm{(in} \mathrm{mg}$ ) yields of four fungal isolates using different carbon sources after 15 days of incubation at $20^{\circ} \mathrm{C}$ and litters contain specific nutrition required by the conidial fungi (Thornton, 1963, Garnett et al., 2000).

In the present study, out of eight carbon sources glucose supported maximum growth of $P$. submersus and $F$. penicillioides. The remaining fungal isolates also showed comparatively higher growth. These observations confirm the study of Ranzoni (1951) on glucose as a good source of carbon for the growth of Anguillosora longissima and A. gigantean. Thornton (1963) similarly

found glucose as a good source of carbon for the growth of Articulospora tetracladia, F. penicillioides, Tricladicum angulatum and $\mathrm{T}$. splendens etc.

Starch, fructose and dextrin are good source of carbon for the growth of P. submer sus and T. marchalianum (Fig. 1). Sucrose supports maximum growth of T. elegans as well as of T. marchalianum and moderate growth of $P$. submersus and $F$. penicillioides. These results support the findings of Ranzoni (1951). Thornton (1963) also 


\section{T.elegans}
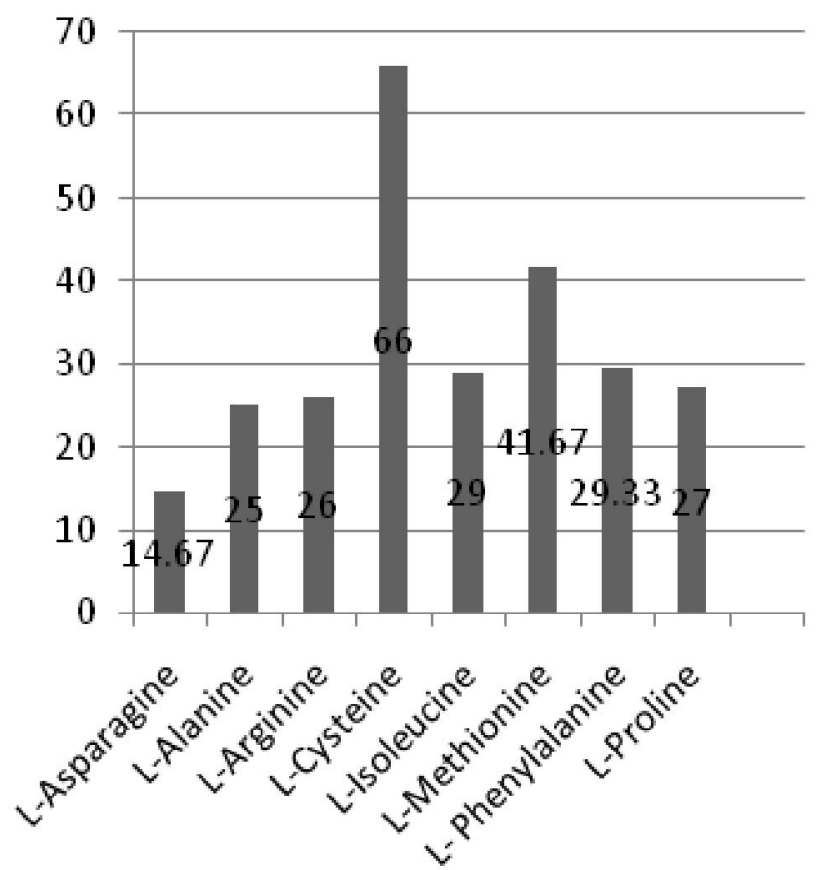

\section{P.submersus}
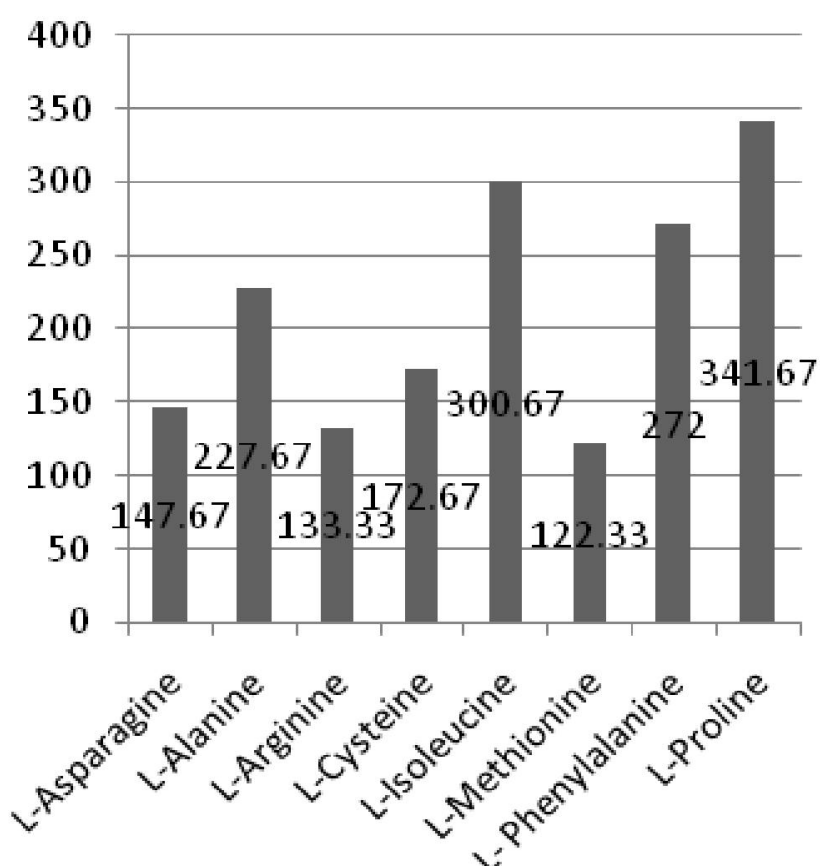
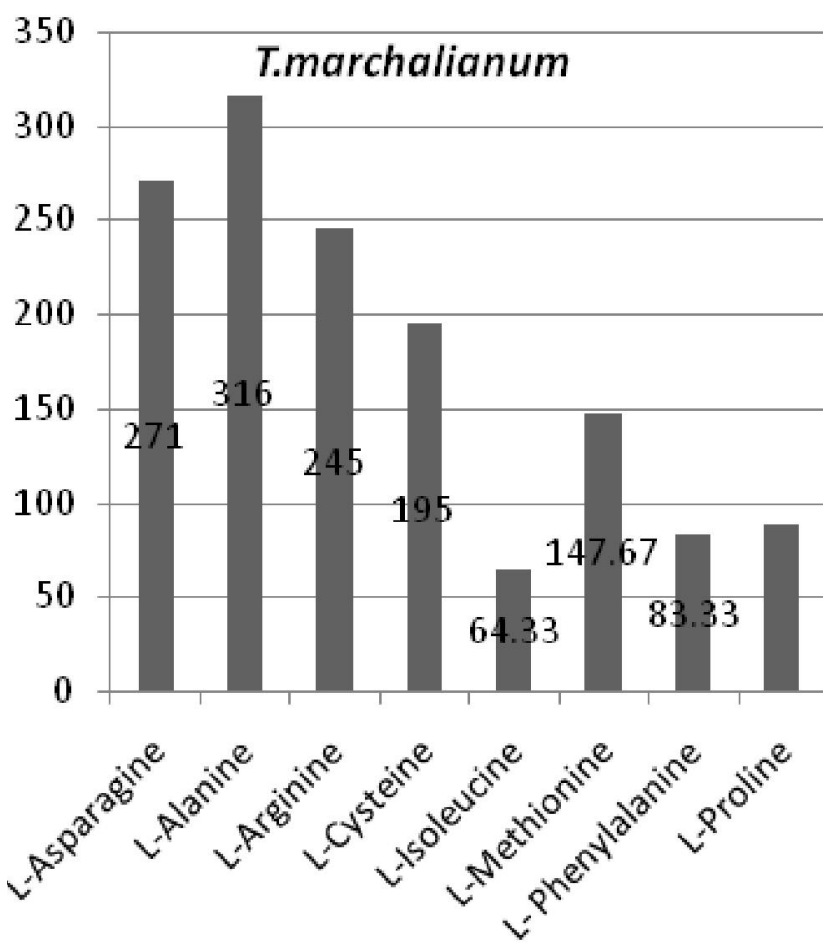

\section{F. penicillioides}
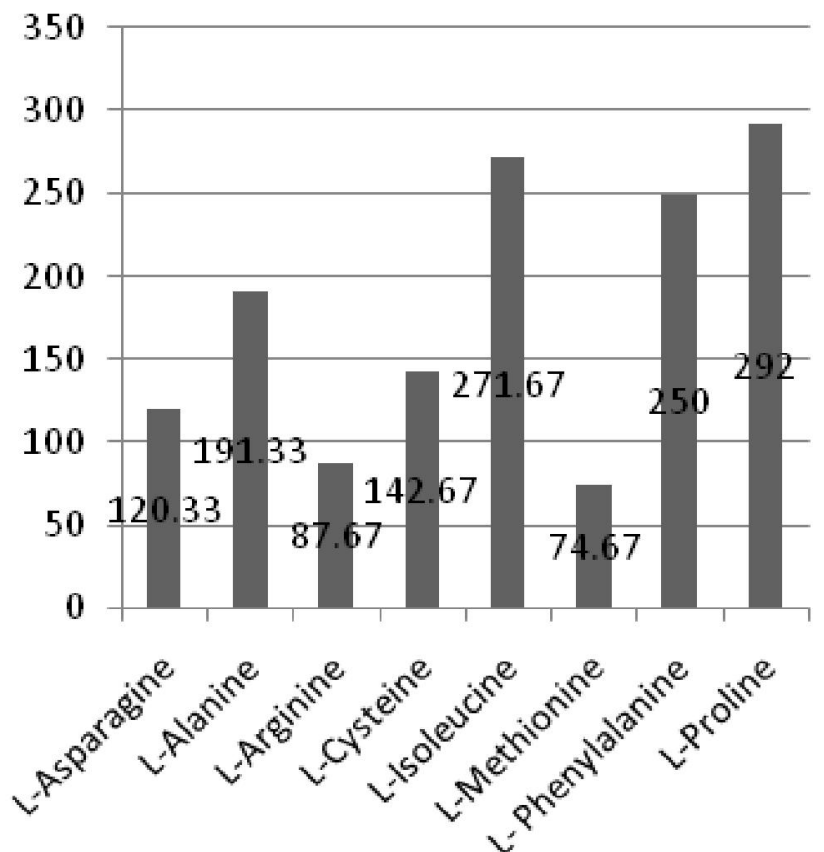

Fig 2. Average dry weight (in mg) yields of four fungal isolates using different amino acids after 15 days of incubation at $20^{\circ} \mathrm{C}$.

reported that fructose, xylose and starch are good sources of carbon for some species of aquatic hyphomycetes. He concluded that starch can be an alternative source of carbon for these fungi.

It is interesting to note that cellulose is a poor source of carbon for the growth of these fungi (Fig. 1). This supports Ranzoni (1951), who also recorded the absence of growth of A. gigantean and A. Iongissima in cellulose as a source of carbon in medium. These fungi probably lack enzyme necessary to degrade cellulose. The fast colonization of these fungi on leaf litter might be explained on the basis of the availability of nutrients and polysaccharides preferred by them (Gulis and Subercropp, 2004).

ANOVA calculated for the observed data showed significant variations in the dry weight production of different fungal species grown with different carbon sources $(\mathrm{p}<0.01)$, indicating that different fungal species have different priorities for their carbon sources. 
Aquatic hyphomycetes utilize inorganic nitrogen leached from the soil into streams more aptly than water moulds (eg. Oomycetes) (Thornton 1963, Mer, 1982). In the present study, all tested fungi could assimilate ammonium ions and nitrate ions as a source of nitrogen with a higher preference for ammonium ions. This has also been supported by Thornton $(1963,1965)$.

In the present study the growth responses of $P$. submersus, T. elegans and T. marchalianum to two inorganic and eight organic nitrogen sources were tested for the first time. Similar studies were made by Thornton (1965) who observed a maximum biomass yield of $A$. tetracladia and F. penicilliodes with aspartic acid and tyrosine, respectivety. All hyphomycetes examined by him were found capable of utilizing arginine, asparagines and other amino acids. Thus the results of the present study support maximum growth of water moulds (Mer, 1982). Proline, phenylalanine, methionine, isoleucine and cysteine were used here for the first time to test the nitrogen nutrition of aquatic hyphomycetes.

Summarising the results it was concluded that nitrogen utilisation of aquatic hyphomycetes distinctly varies from species to species. In contrast to the fungus like water moulds, aquatic hyphomycetes are capable of utilising a wide range of inorganic and organic nitrogen sources, which are leached from leaf litter or soil into streams (Garnet et al., 2000). Old leaf litter and green leaves serve as source for both carbon and nitrogen in the form of amino acids. The preferential utilization of amino acids by aquatic hyphomycetes (Thornton 1965) may explain their frequent prevalence on decomposing leaf litter.

\section{ACKNOWLEDGMENTS}

My special thanks to Prof. S.C. Sati, Department of Botany, Kumaun University, Nainital, for providing laboratory facilities and his valuable guidance.

\section{REFERENCES}

Barlocher, F. and Corkum, M. (2003). Nutrient enrichment overwhelms diversity effects in leaf decomposition by stream fungi. Oikos, 101: 247-252.

Dang, C.K., Chauvet, E. and Gessner, M.O. (2005). Magnitude and variability of process rates in fungal diversity-litter decomposition relationships. E cology Letters, 8: 1129-1137.

Field, J. (1985). Effect of sulphide on survivial of aero-aquatic and aquatic hyphomycetes. Transactions of the British Mycological Society, 85(2): 193-199.

Garnett, H., Balocher, F. and Giberson, D. (2000). Aquatic hyphomycetes in catamaran Brook: Colonization dynamics, seasonal patterns and logging effects. M ycologia, 92: 20-41.

Gulis, V. I. and Stephanovich, A.I. (1999). Antibiotic effects of some aquatic hyphomycetes. M ycological Research, 103(1): 111-115.
Gulis, V. I. and Suberkropp, K. (2004). Effects of whole- stream nutrient enrichment on the concentration and abundance of aquatic hyphomycetes conidia transport. M ycologia, 96(1): 57-65.

Ingold, C.T. (1942). Aquatic hyphomycetes of decaying alder leaves. Transactions of the British M ycological Society, 25 339-417.

Ingold, C.T. (1975). An illusttated guide to aquatic and waterbone hyphomycetes (Fungi imperfecti) with notes on their biology. Freshwater Biological Association Scientific publication, England.

Manoharachary, C. (1986). Aspects and prospects of water borne conidial fungi from India. Advances in Biological Research, 4(1 and 2): 160-183.

Marvanova, L. (1997). Freshwater hyphomycetes: a survey with remarks on tropical taxa. In: K.K.Janardhanan, C. Rajendran, K. Natrajan, D.L. Gawksworth (Ed.), Tropical Mycology (pp 169-226), U.S.A.: Science Publishers.

Mer, G. S. (1982). Taxonomic and physiological studies of water molds of Sattal (Nainital), Ph.D. Thesis, Kumaun University, Nainital, India.

Ranzoni, F. V. (1951). Nutrient requirements for two species of aquatic hyphomycetes. M ycologia, 43:130-141.

Sati, S.C. and Tiwari, N. (1997). Glimpses of conidial aquatic fungi in Kumaun Himalaya. In: S.C.Sati, J.Saxena, R.C. Dubey (Ed.), Himalayan Microbial Diversity (pp 17-33), New delhi: Today and Tomorrow's Printers and Publisher.

Sati, S.C., Tiwari, N. and Belwal, M. (2002). Conidial aquatic fungi in Kumaun Himalaya, India. M ycotaxon, 80: 445-455.

Sati, S.C. and Joshi, S. (2011). Aquatic hyphomycetes and its anamorph (asexual stage)- teleomorph (sexual stage) relations: A review. The International J ournal of plant Reproductive Biology, 3(2): 1-10

Sridhar, K.R., Chandrashekhar, K.R., Kaveriappa, K.M. (1992). Research on the Indian Sub-continent. In: F Barlocher (Ed.), The Ecology of Aquatic Hyphomycetes (pp182-211), Heidelberg: Springer-Verlag.

Sridhar, K. R., Raviraja, N. S. (1995). Endophytes- A crucial issue. Current Science, 69: 570-571.

Suberkropp, K. (1984). Effect of temperature on seasonal occurrence of aquatic hyphomycetes. Transactions of the British M ycological Society, 82: 53-62.

Thompson, P.L. and Barlocher, F. (1989). Effect of pH on leaf breakdown in streams and in the laboratory. J ournal of North American Benthological Society, 8: 203-210.

Thornton, D.R. (1963). The physiology and nutrition of some aquatic hyphomycetes. J ournal of General Microbiology, 33: 23-31.

Thornton, D.R. (1965). Amino acid analysis of fresh leaf litter and the nitrogen nutrition of some aquatic hyphomycetes. Canadian J ournal of M icrobiology, 11: 647-662.

Webster, J. and Descals, E. (1981). Morphology, distribution and ecology of conidial fungi in fresh water habitats. In: G.T.Cole, B. Kendrick (Ed.), The Biology of Conidial Fungi (pp 295-355), New York: N.Y.Academic Press. 